\title{
Temporal pattern of foraging and microhabitat use by Galápagos marine iguanas, Amblyrhynchus cristatus
}

\author{
William A. Buttemer*, William R. Dawson \\ Department of Biology, Museum of Zoology, University of Michigan, Ann Arbor, MI 48109, USA
}

Received: 22 June 1992 / Accepted: 10 June 1993

\begin{abstract}
We observed a colony of marine iguanas (Amblyrhynchus cristatus) on Isla Fernandina, Galápagos, Ecuador, while measuring local micrometeorological and tidal conditions. We found size-related differences in foraging mode, with smaller iguanas feeding intertidally during daytime low tides and larger iguanas feeding subtidally. Despite having greater opportunity, subtidal foragers did not time their foraging bouts or exploit their environment in ways that optimized their period at high body temperature. Instead, the foraging schedule of these iguanas served to maximize their rate of rewarming following emergence from the cool sea. Intertidal feeders, by contrast, showed much greater behavioral flexibility in attempting to exploit their thermal environment. We suggest that size-ordered differences in marine iguana thermoregulatory behavior reflect underlying ontogenetic changes in costs and benefits of thermoregulation due to differences in predator pressure, quantity of food and electrolytes taken at each feeding, mode of foraging, and agonistic tendencies.
\end{abstract}

Key words: Marine iguanas - Foraging - Thermoregulation - Micrometeorology - Operative temperature

Many aquatic vertebrates show ontogenetic shifts in habitat use that are usually associated with changes in predation risks relative to foraging gains as individuals increase in size (Werner and Hall 1988). Size-ordered differences in foraging sites are also found in the herbivorous marine iguana (Amblyrhynchus cristatus), with lizards weighing less than $1.2 \mathrm{~kg}$ being restricted to intertidal foraging sites and those larger than $1.2 \mathrm{~kg}$ able to exploit subtidal sites for grazing (Trillmich and Trillmich 1986). These foraging differences in these Galápagos animals, however, are probably due more to functional requirements for effective swimming than to predator pressure.

\footnotetext{
* Present address: Department of Biological Sciences, University of Wollongong, Wollongong, NSW 2500, Australia

Correspondence to: W.A. Buttemer
}

Because both speed and power generated per body undulation while swimming are directly related to overall size of marine iguanas (Vleck et al. 1981), smaller lizards would have to undulate more rapidly than larger iguanas to overcome waves and tidal surges and, thus, would be much more prone to fatigue. Large lizards, by contrast, are able to swim to offshore foraging sites and return to land about $45 \mathrm{~min}$ later with little indication of an oxygen debt (Gleeson 1980a).

The constant availability of submarine algae permits subtidal feeders to schedule their foraging bouts freely, whereas the dependence of intertidal grazers on exposure of algal encrusted rocks dictates that their feeding occur during low tides (Trillmich and Trillmich 1986). Because these intertidal feeding sites attract much greater densities of foraging lizards than subtidal locations (Trillmich and Trillmich 1986), larger iguanas presumably consume more macrophytic algae per unit effort than intertidal foragers. This presents an interesting situation regarding potential size-related differences in thermoregulatory activities by these iguanas. Marine iguanas have long been known to behaviorally thermoregulate (Bartholomew 1966; White 1973). They do this mainly by adjusting rates of heat gained from basking in the equatorial sun against convective heat losses associated with the moderate diurnal air temperatures of the Galápagos. The adjustments are accomplished through microhabitat selection and postural adjustments. Because subtidal foragers do not have to time their feeding to coincide with low tides, they may schedule their forays to maximize periods of high preferred body temperature on land in order to facilitate digestion, assimilation, and various homeostatic processes. Intertidal feeders, by contrast, would have to disrupt their terrestrial thermoregulatory activities whenever tidal recesses exposed their feeding sites, a circumstance that makes them much more temporally constrained in thermoregulatory activities than larger conspecifics.

An evaluation of the efficacy of thermoregulation by subtidal foragers requires knowledge of their spatiotemporal relations to their terrestrial environment as well as characterization of the thermal environments available to them. Accordingly, we undertook this study of a marine iguana colony which integrates observations of the activities of lizards on land and in water with measurements of local meteorological and tidal conditions. 


\section{Material and methods}

\section{Study site}

After a survey around several of the Galápagos Islands, we selected a small peninsula about $3 \mathrm{~km}$ south of Punta Espinosa, Isla Fernandina, for our study site (latitude $0.3^{\circ} \mathrm{S}$, longitude $91.4^{\circ} \mathrm{W}$ ). This location was chosen because it was frequented daily by as many as 150 juvenile and adult marine iguanas and because its complex topography afforded them a range of microhabitats. We mapped the site and delineated 10 discrete study areas within it, based on salient physical features (Fig. 1), such as orientation and slope (Table 1).

\section{Meteorological measurements}

Global and reflected radiation were measured with Eppley black and white pyranometers. The pyranometer used to measure reflected radiation was calibrated in its inverted position according to the methods of Norris (1974). Diffuse solar radiation was measured with an Eppley black and white pyranometer fitted with an occluding ring, which shaded the pyranometer from direct sunlight. Values for

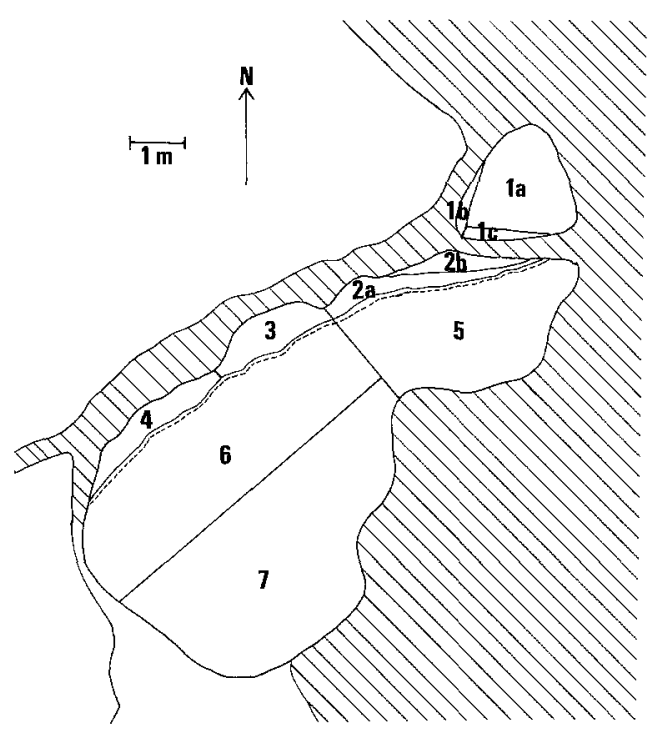

Fig. 1. Overhead view of study site. Study areas are designated by numbers and letters. Sea water surrounding the site is represented by diagonal lines and the crest of the peninsula is delineated by the dashed line

Table 1. Average slope aspects of the 10 study areas

\begin{tabular}{lll}
\hline Study area & $\begin{array}{l}\text { Slope azimuth } \\
\text { Angle (deg.) }\end{array}$ & $\begin{array}{l}\text { Slope altitude } \\
\text { Angle (deg.) }\end{array}$ \\
\hline $1 \mathrm{a}$ & 75 & 65 \\
$1 \mathrm{~b}$ & 250 & 10 \\
$1 \mathrm{c}$ & 172 & 10 \\
$2 \mathrm{a}$ & 323 & 30 \\
$2 \mathrm{~b}$ & 341 & 65 \\
3 & 306 & 20 \\
4 & 300 & 25 \\
5 & 159 & 50 \\
6 & 124 & 62 \\
7 & 124 & 41 \\
\hline
\end{tabular}

diffuse radiation were corrected for the portion of the sky blocked by this ring (G.S. Bakken, pers. comm.). We estimated direct solar irradiation of the 10 study sections using the formulations of Gates (1980), average slope altitudes and azimuth angles of the 10 locations (Table 1), and our measurements of direct solar radiation on a horizontal surface (Fig. 1).

Wind speed was measured using hot-ball anemometers (Buttemer 1981). These were calibrated before and after field use, using a laminar-flow wind tunnel fitted with a Gill 4-vane anemometer (R.M. Young Co.) as a reference. Three anemometers each were attached to two thin-walled conduits and placed $0.3,1.0$, and $1.6 \mathrm{~m}$ above the surface of the lava substrate. These anemometer towers were placed on opposite sides of the study site (areas 3 and 6 ; Fig. 1). A separate group of 4 hot-ball anemometers and thermocouples were attached to a rectangular frame which was moved about the colony. Anemometers on this ladder were spaced $4.5,15,25.5$, and $45 \mathrm{~cm}$ above ground level and the 4 thermocouples were spaced $2,12.5,23$, and $43 \mathrm{~cm}$ above ground level.

Wind direction was monitored with a wind vane positioned $4 \mathrm{~m}$ above the surface between the two anemometer stands. A continuous-turn potentiometer attached to the base of the vane formed part of an electrical circuit whose voltage output varied as a function of wind direction.

Air temperature $\left(T_{a}\right)$ at the height of each anemometer was measured using shaded, butt-welded 36 ga copper-constantan (Cu-Cn) thermocouples. These were calibrated, using the same recording system, against a previously calibrated mercury-in-glass thermometer. Surface temperatures $\left(T_{s}\right)$ at 3 locations were monitored with 22 ga $\mathrm{Cu}-\mathrm{Cn}$ thermocouples cemented to the substrate using epoxy resin mixed with substratum to color-match the particular site. All meteorological data were recorded at 10-min intervals using a Kaye System 8000 precision voltage recorder. Electrical power was supplied by a Honda $2.5 \mathrm{kVA}$ generator fitted with a frequency-conditioning circuit.

\section{Operative temperature evaluation}

Measurement of the equilibrium temperature of an object sharing the physical characteristics of an animal's surface and dimensions provides one way to measure its operative environmental temperature $\left(\mathrm{T}_{e}\right.$; Bakken and Gates 1975). Because the body temperature $\left(T_{b}\right)$ of inactive lizards primarily results from thermal exchanges between the animal's surfaces and their environment, $T_{e}$ measured at sites shared by lizards will closely approximate their $T_{b}$. Accordingly, we made isometric models of a $1.1 \mathrm{~kg}$ marine iguana following methods outlined by Bakken and Gates (1975). Selection of an iguana this size was influenced by two considerations; firstly, it was most representative of the iguanas at our study site and, secondly, it was near the upper size limit for our casting and electroplating capabilities. This modelling procedure involves making a negative mold of the iguana using alginate impression material (Jeltrate Type II) and then pouring microcrystalline casting wax into the mold to make a life-sized replica of the lizard. Before making the mold, the iguana was immobilized by chilling it overnight until its $T_{b}$ was about $3^{\circ} \mathrm{C}$. Two wax replicas were made of the animal in its prostrate basking posture. Forty-eight $h$ later, following its full recovery, two more castings were made with this lizard in its elevated basking posture (see Bartholomew 1966 for description of postures). Thermocouples attached to $1-\mathrm{cm}$ wide strips of copper sheet were inserted laterally at three locations in each model: midline through the head, thorax, and abdomen of each wax replica. The copper strips were trimmed to the cast's wax surface, which was scribed to accommodate later addition of a length of $\mathrm{Cn}$ wire and then painted with an electrically-conductive silver paint (Electrodag 415; Acheson Chemical Co.). After electrodepositing one layer of copper on the cast, an electrically-insulated length of $\mathrm{Cn}$ was affixed to the tract previously scribed and a thin layer of polyester resin was then added to strengthen the cast. The cast was then repainted with Electrodag 415 and coated with a second layer of copper. Following removal of wax from each copper replica, their surfaces were painted to color-match live iguanas. The reflectivity of replica and 
live iguana surfaces was evaluated over the spectral range of 350-1550 nm using an ISCO spectroradiometer (model SR) with a fiber optic detector. For these measurements, we placed the detector in a columnating cylinder and compared the reflectance of the animal and model surfaces to known standards $\left(\mathrm{BaSO}_{4}\right.$; Eastman Kodak Nextel flat black; Eastman Kodak gray card) in sunlight.

We placed the completed models at the same location and orientation at study area 6 for half a day and recorded their temperatures at 10 -min intervals to check the level of thermal agreement between duplicate castings. After this trial period, models were moved to sites most often used by subtidal foragers at study areas $3,4,5,6$, and 7 for the next 3 days. Operative temperatures were calculated by weighting temperatures measured at the three locations in each replica by the relative body volume associated with each thermocouple site. Overall thermal conductances $\left(\mathrm{K}_{\mathrm{e}}\right.$, Bakken 1976b) associated with models at various field sites were determined from cooling rates of heated models. Models were heated by providing a $\mathrm{DC}$ voltage to the embedded $\mathrm{Cn}$ wire until the model lizards were $15-20^{\circ} \mathrm{C}$ warmer than preheated values. At this time, we switched off the DC power source and recorded their body temperatures at $5 \mathrm{~s}$ intervals until these values stabilized.

We evaluated effective surface areas for absorption of direct solar radiation of elevated and prostrate basking models using photometric methods. This procedure involved photographing each lizard model at a fixed distance at camera zenith angles ranging from $0^{\circ}$ and $90^{\circ}$. The surface areas associated with the photographic negatives of the models were quantified using a photoplanimeter (Quantimet 720 Image Analyzer).

\section{Behavioral observations}

We surveyed each of the 10 study areas, as well as nearshore and offshore locations adjoining the study site, from a distance that did not disturb the iguanas. These observations, made between 1 and 22 July, commenced near sunrise and were repeated at ca. 15-min intervals on most days until sunset. For each observation period, we noted the number of animals at each area, their posture and orientation, whether they were wet or dry, and the number of lizards that were feeding. Those iguanas seen grazing on exposed rocks nearshore were classified as intertidal foragers and those observed freeswimming and periodically diving were termed subtidal foragers. We also censused the study site on several nights and again the next morning before first light to evaluate how mobile animals were through the night.

Values reported below are given as means plus or minus one standard error unless stated otherwise.

\section{Results}

\section{Foraging times}

We have complete daily records of intertidal and subtidal foraging for 14 and 17 days, respectively, over the course of our study. The mean time of day associated with foraging subtidally or intertidally was determined by summing the product of the number of individuals seen feeding and the time of day that the observations were made over the course of the day. As expected, mean feeding times of intertidal foragers were significantly correlated with tidal phase (Fig. 2). During tidal lows, very few subadult iguanas were seen ashore. For intertidal foragers, the relation between mean feeding time $\left(t_{\mathrm{f}}\right.$ in $\left.\mathrm{h}\right)$ and time of low tide $\left(\mathrm{t}_{\mathrm{lt}}\right.$ in $\left.\mathrm{h}\right)$ is described by the relation:

$\mathrm{t}_{\mathrm{f}}=1.3+0.8 \mathrm{t}_{\mathrm{lt}}$

$\left(\mathrm{r}=0.99 ; P<0.001 ; \mathrm{s}_{\mathrm{b}}=0.026 ; \mathrm{s}_{\mathrm{y} \cdot \mathrm{x}}=0.39 ; N=14\right.$ days $)$

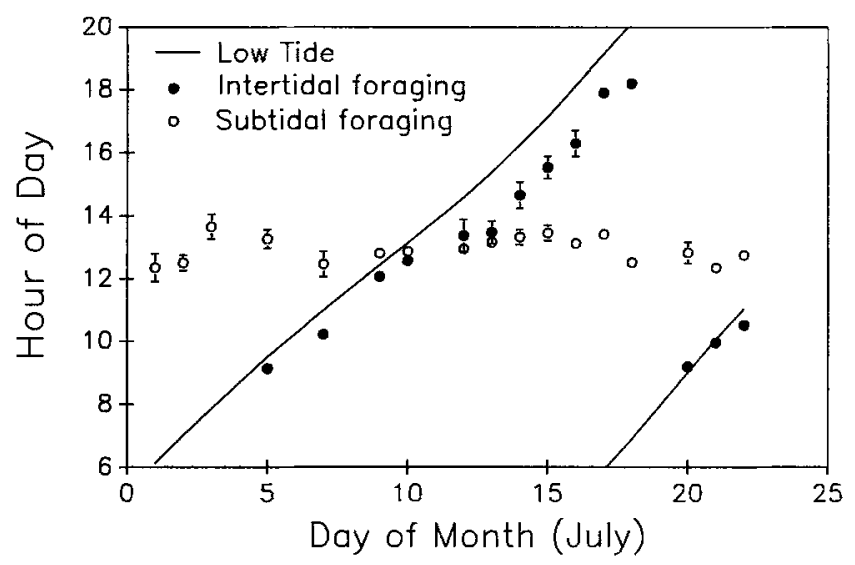

Fig. 2. Low tide and marine iguana foraging times over the course of our study. The vertical bars represent $95 \%$ confidence limits for the daily mean values presented

Subtidal feeders, by contrast, fed independently of tidal cycle and showed a predictable diurnal feeding pattern with a daily mean time of $1303 \mathrm{~h}( \pm 6 \mathrm{~min}$; range $=1207$ to $1339 \mathrm{~h} ; N=17$ days) (Fig. 2). For three large male lizards (mean mass $=2.9 \pm 0.3 \mathrm{~kg}$ ) that were individually marked as part of another study (G.A. Bartholomew and D. Vleck, pers. comm.), the mean time of water entry was $1234 \mathrm{~h} \mathrm{(} \pm 19 \mathrm{~min} ; n=14$ observations) and the mean time of emergence from feeding was $1316 \mathrm{~h}$ ( $\pm 11 \mathrm{~min} ; n=10$ observations). Daylength at this equatorial site was nearly constant throughout our 3-week study.

\section{Micrometeorological conditions}

Air temperature, measured from 30 min after sunrise until $30 \mathrm{~min}$ before sunset at a height of $0.5 \mathrm{~m}$, averaged $24.5 \pm 0.06^{\circ} \mathrm{C}$ over the course of our study. Nighttime air temperatures, measured $30 \mathrm{~min}$ after sunset until $30 \mathrm{~min}$ before sunrise, averaged $20.8 \pm 0.04^{\circ} \mathrm{C}$ over the study period. Nocturnal temperatures of easterly and westerly exposed surfaces (areas 4 and 6) did not differ significantly $(P>0.6)$ and averaged $22.0 \pm 0.05^{\circ} \mathrm{C}$. During daylight, however, surface temperatures at these two sites differed significantly $(P<0.001)$ and averaged $34.8 \pm 0.18$ and $32.3 \pm 0.15^{\circ} \mathrm{C}$ at sites 4 and 6 (Fig. 1), respectively. The average daily surface albedo measured at area 6 between 1100 and $1300 \mathrm{~h}$ was $0.169 \pm 0.001$.

Because the 10 study areas had different slope aspects (Table 1), insolation varied both quantitatively and temporally among these sites (Fig. 3). For example, for two sites that had comparable solar radiative loadings (1a and $3 \mathrm{~s}$ ), the peak solar receipt at both sites was nearly $4 \mathrm{~h}$ apart (Fig. 3). To generalize, sites with easterly to southeasterly aspects (areas 1a, 5,6, and 7; Fig. 1) had peak insolation before midday. In contrast, sites with more north-westerly aspects (areas $2 \mathrm{a}$ and $2 \mathrm{~b}$; Fig. 1) received strongest solar radiation near midday and those with more westerly orientation (areas 3,3s; a horizontal shelf at area 3 with a $45^{\circ}$ slope, and 4; Fig. 1) had greatest solar insolation after 1300 until nearly $1600 \mathrm{~h}$. Area 1c (Fig. 1) 
rarely received more than $200 \mathrm{~W} / \mathrm{m}^{2}$ on clear days because of its slope and shading by the adjacent cliff. Area $1 \mathrm{~b}$, in contrast, received direct sun only after $1400 \mathrm{~h}$.

Local differences in wind speed were also noted between easterly and westerly slopes. Throughout our study, there was a pattern of gusty southeasterly winds in early morning hours lasting until about midday. This pattern was so consistent that out of 17 days for which we have complete diurnal wind records, 15 had wind direction shift from E-SE to NW at a modal time of $1159 \mathrm{~h} \pm 20 \mathrm{~min}$ (range $=1000$ to $1530 \mathrm{~h}$ ). During the two days lacking this pattern, southeasterly winds persisted all day. These shifts in wind direction, from E-SE to NW, were also accompanied by abrupt reduction in wind speed (Fig. 4). For example, for the 15 diurnal windshifts we recorded, the average wind speed at $0.5 \mathrm{~m}$ above the

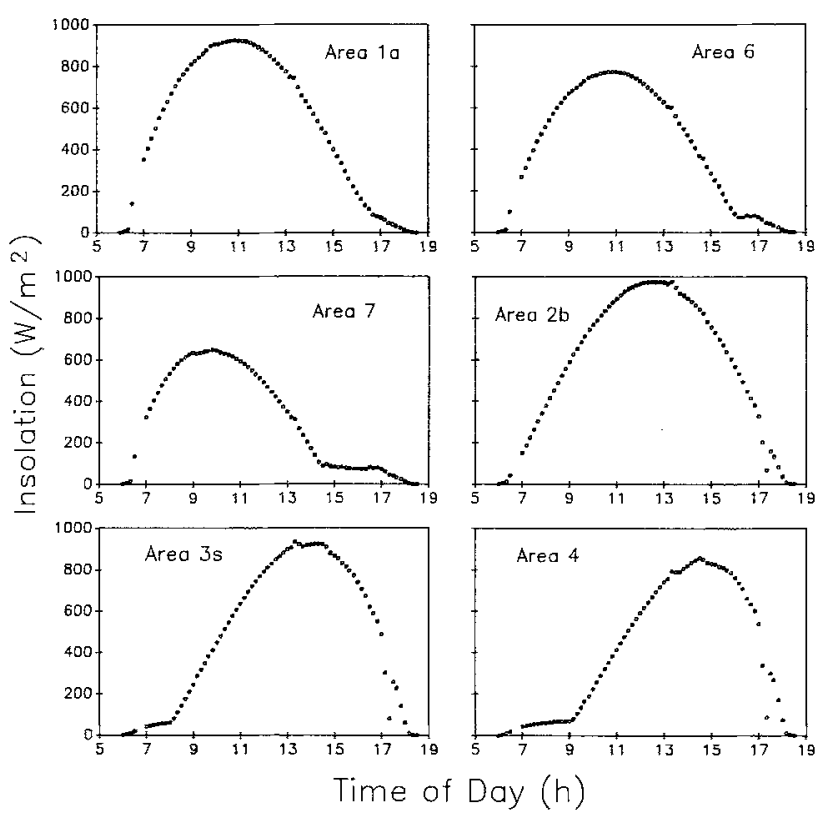

Fig. 3. Total solar radiation (direct plus diffuse) received by six of the study areas on 1 July

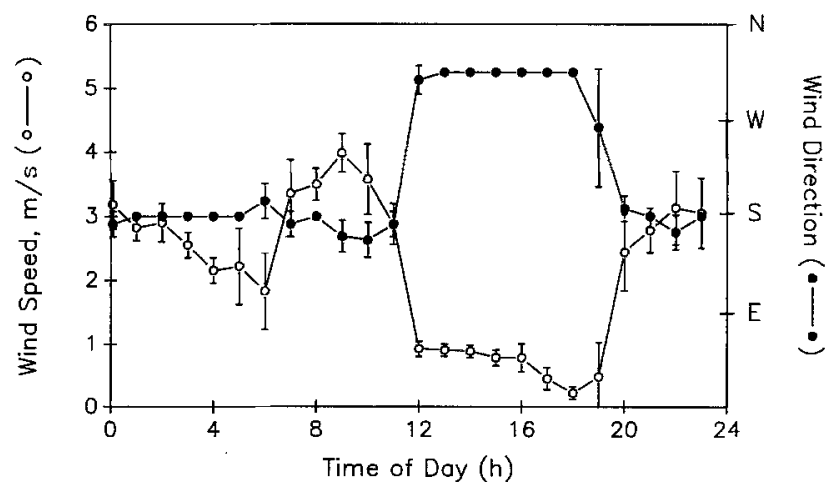

Fig. 4. Wind speed and wind direction measured at $0.5 \mathrm{~m}$ above the surface of study areas 6 on 20 July. Vertical bars designate $95 \%$ confidence limits for the hourly means depicted surface at area 6 was $3.43+0.18 \mathrm{~m} / \mathrm{s}$ when the wind was from the E-SE and $0.74 \pm 0.04 \mathrm{~m} / \mathrm{s}$ when it shifted to the NW. During periods of E-SE winds, wind speeds measured $0.5 \mathrm{~m}$ to the west of area 3 and ca. $1 \mathrm{~m}$ below its crest averaged $0.63 \pm 0.05 \mathrm{~m} / \mathrm{s}$. This latter area was often frequented by iguanas basking after midday foraging.

\section{Temporal pattern of land use by Marine Iguanas}

Given the heliothermic nature of marine iguanas (Bartholomew 1966; White 1973), we were surprised to find that most lizards were not distributed in a manner permitting maximal insolation at dawn. On average, less than a quarter of the lizards used sites with easterly to southeasterly orientations early in the day (areas 1a, 5,6, and 7; Fig. 1). Most use of these areas was, in fact, deferred until about $1100 \mathrm{~h}$. The typical daily progression was for lizards, particularly subadults, to congregate mostly at north to northwesterly sites which were partially protected from easterly winds $(2,2 a)$ until midday and then, depending on how long they had been basking, to shift to either easterly $(1 \mathrm{a}, 5,6,7)$ or westerly $(3,4,1 \mathrm{~b})$ locations. Those lizards exhibiting elevated basking postures (Bartholomew 1966) were usually seen at the easterly sites. On days with low wind, many lizards at these sites would exaggerate this posture by placing their forelegs on raised lava and pointing their heads directly to the sun as described by Bartholomew (1966) and White (1973).

Iguanas feeding subtidally returned mainly to areas 3 and 4 (Fig. 1) following foraging. Basking locations used by intertidal feeders were more variable, but tended to be clustered near areas $2 \mathrm{a}$ and 2 when animals fed in the morning through midday and near areas $2 a, 1 b$, and 3 (Fig. 1) when they fed later. After a suitable period of post-prandial basking, iguanas tended to shift to areas $1 \mathrm{a}, 5,6$, and 7 until about $1500-1600$. At this time, many iguanas moved to westerly sites (1b,3, and 4; Fig. 1) and remained there until the following morning. On most evenings, dense clusters of subadult iguanas assembled along a shelf between areas 3 and 4 and remained there until the following morning. We did not see large adult male iguanas in these nocturnal clusters.

\section{Operative temperatures}

Based on the field spectral reflectance measurements, the effective solar absorptance of models and live iguanas averaged $0.976( \pm 0.004)$ and $0.955( \pm 0.006)$, respectively. These values were derived by applying a finite approximation to equation 3 of Porter and Gates (1969) and used a solar spectral irradiance representative of sea level and an airmass of 1.5 (Bakken et al. 1978). The similar solar absorptances of living and model iguanas would cause operative temperatures of the models to approximate closely those of similar-sized live iguanas. Although the lizard chosen for casting was of smaller mass than subtidal foragers, its external dimensions differed to a lesser extent. Considering that convective heat exchange is related to the square root of an object's diameter (Gates 1980), the square root of head, thorax, and foreleg diameters of 
a $3 \mathrm{~kg}$ iguana averaged only $22 \pm 0.3 \%$ higher than those for a $1 \mathrm{~kg}$ lizard. Thus, although $\mathrm{T}_{\mathrm{e}}$ of a $1.1 \mathrm{~kg}$ lizard will be somewhat different than that of a $3 \mathrm{~kg}$ one, evaluations of $T_{e}$ made using models of a $1.1 \mathrm{~kg}$ iguana are pertinent to those of subtidal foragers.

Comparison of $T_{e}$ for two prostrate basking models over the course of a day reveals striking thermal differences between areas 6 and 3 (Fig. 5). The model at area 6 (M-4; Fig. 5) warmed up earlier than the one at area 3 (M-1; Fig. 5) but its $T_{e}$ remained much lower than that of M-1 for most of the diurnal period. The abrupt rise in M-4's $T_{e}$ after 1200 (Fig. 5) was coincident with the typical change in wind direction and wind speed occurring at midday (Fig. 4). These midday $\mathrm{T}_{\mathrm{e}}$ 's for the prostrate basking models were higher than the 35 to $37^{\circ} \mathrm{C}$ range of body temperatures preferred by marine iguanas (Bartholomew 1966). However, the operative temperature of an iguana model in the elevated basking posture remained between 30 and $35^{\circ} \mathrm{C}$ from 1100 until $1600 \mathrm{~h}$ (Fig. 6). The latter model (M-3) was situated near the crest of area 6 (Fig. 1)

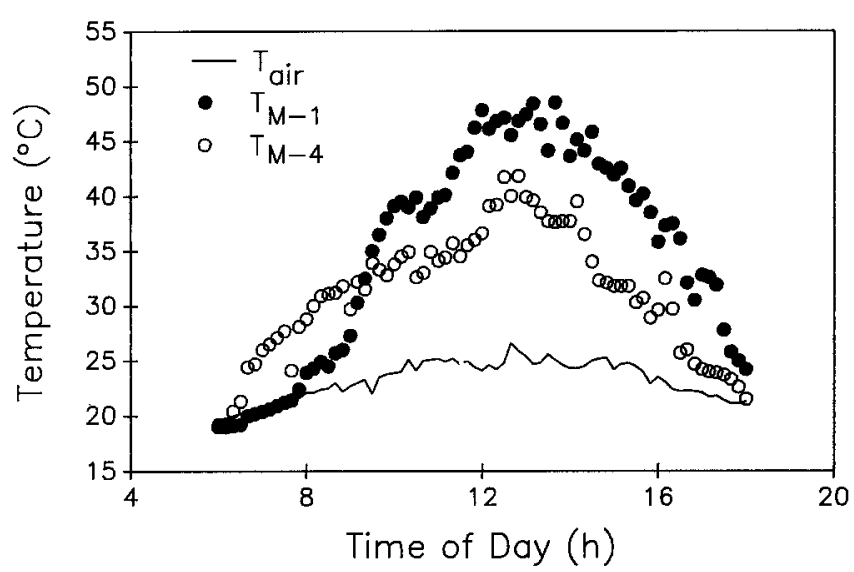

Fig. 5. Daytime air and operative temperatures for marine iguanas for 20 July. Both iguana models were in prostrate basking postures. M-1 was located at study area 3 and M-4 at study area 6

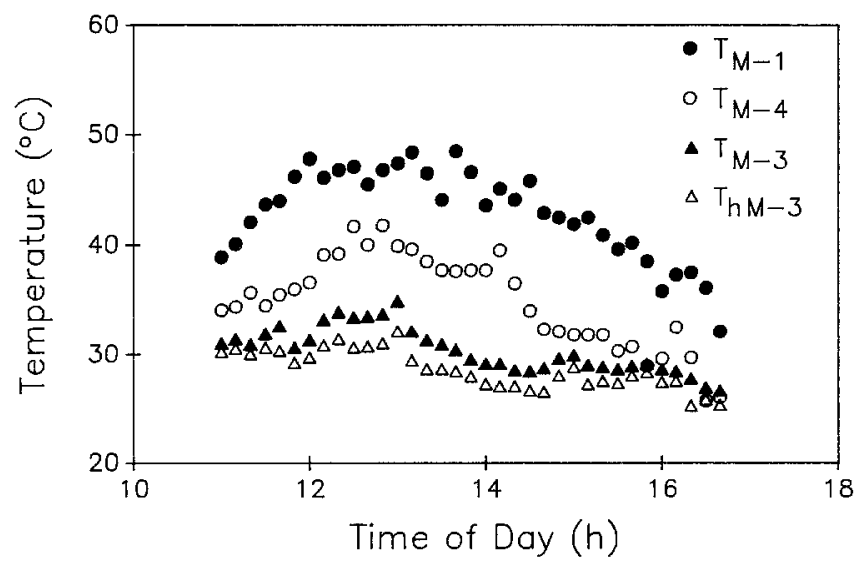

Fig. 6. Midmorning to late afternoon operative temperatures for two marine iguana models in prostrate basking postures (M-1 at study area $3 ; \mathrm{M}-4$ at study area 6 ) and for a model in the elevated basking posture (M-3 at study area 6 ) on 20 July. The head temperature of $\mathrm{M}-3$ is also depicted $\left(\mathrm{T}_{\mathrm{hM}-3}\right)$ and positioned with its head pointed to the sun. Consequently the long axis of its body was parallel to incident solar irradiation. After the wind shift at $1220 \mathrm{~h}$, the head temperature of $\mathrm{M}-3$ remained 2 to $3^{\circ} \mathrm{C}$ cooler than its overall $\mathrm{T}_{e}$ for much of the afternoon (Fig. 6).

\section{Discussion}

In their insightful analysis of lizard thermoregulation, Huey and Slatkin (1976) suggested how interspecific and intraspecific differences in level and precision of thermoregulation might result from variation in costs associated with these behaviors. They predicted, for example, that precise thermoregulation is more likely to be associated with lizards living in open habitats than those lacking easy access to basking sites. The persistently high insolation at our equatorial study site, which is in the rain shadow of Volcan Fernandina, provided ample opportunity for solar basking by the resident marine iguanas. These conditions are ideal for permitting subtidal foragers to maximize their periods at high body temperatures, but do they achieve this? The answer is emphatically no. From the standpoint of maximizing periods of high daytime $T_{b}$ 's, the best time to feed would be at first light. The average $T_{b}$ of four adult male iguanas was $20.5 \pm 0.4^{\circ} \mathrm{C}$ just before sunrise (G.A. Bartholomew and D. Vleck, pers. comm.). If these lizards were to enter the water at sunrise, they would gain some heat from the slightly warmer seawater and then return to land approximately $1 \mathrm{~h}$ later and begin basking. Instead, almost all subtidal feeders entered the water after they had warmed above nocturnal levels, only to become cooled again while swimming. This is corroborated by telemetry data for adult male iguanas which had $\mathrm{T}_{\mathrm{b}}$ 's of $36.1 \pm 0.5^{\circ} \mathrm{C}$ just prior to entering the water to feed and $22.4 \pm 0.2^{\circ} \mathrm{C}$ upon coming ashore $50 \mathrm{~min}$ later (G.A. Bartholomew and D. Vleck, pers. comm.).

Another indication that the largest iguanas are not maximizing their daily $T_{b}$ is shown by their habit of spending nights singly and fully exposed. This results in their having lower $\mathrm{T}_{\mathrm{b}}$ 's throughout the night than smaller conspecifics that cluster nocturnally at exposed sites (Boersma 1982) and lower than those associated with similar-sized Galápagos land iguanas (Conolophus pallidus) resting alone in burrows (Christian and Tracy 1985). Although we did not measure $T_{b}$ 's of clustered subadult iguanas, we monitored substrate temperatures at a site where these lizards routinely clustered $2-3$ individuals deep. By $1 \mathrm{~h}$ after sunset, the mean nightly temperature beneath the lizard cluster averaged $31.1 \pm 0.2^{\circ} \mathrm{C}$ which was nearly $9^{\circ} \mathrm{C}$ higher than $\mathrm{T}_{\mathrm{a}}$, but indistinguishable $(P>0.4)$ from $\mathrm{T}_{\mathrm{b}}$ 's of large single males containing temperature transmitters (G.A. Bartholomew and D. Vleck, pers. comm.). By midnight, however, $\mathrm{T}_{\mathrm{b}}$ 's of solitary large iguanas approximated $\mathrm{T}_{\mathrm{a}}$ (both about $21^{\circ} \mathrm{C}$ ) whereas temperatures beneath the subadult iguana cluster averaged $26.2 \pm 0.2^{\circ} \mathrm{C}$.

An appreciation of how much the large iguanas may underutilize the thermal resources of their habitat is gained by comparing the telemetered $\mathrm{T}_{\mathrm{b}}$ 's of a large male iguana that remained mostly at one location for over $24 \mathrm{~h}$ with hourly maximal diurnal $T_{b}$ 's that were recorded for 
similar-sized iguanas over a range of locations during the course of our study (G.A. Bartholomew and D. Vleck, pers. comm.; Fig. 7). The nocturnal $\mathrm{T}_{\mathrm{b}}$ 's used for this composite are based on values expected for an individual clustering with conspecifics instead of resting singly. The average $24-\mathrm{h} \mathrm{T}_{\mathrm{b}}$ of the sessile iguana was $27.2 \pm 1.3^{\circ} \mathrm{C}$. This is significantly lower than the $\mathrm{T}_{\mathrm{b}}$ it could attain $\left(31.6 \pm 1.4^{\circ} \mathrm{C} ; P<0.001\right)$ if it were to move around the study site throughout the day and cluster with others at night (Fig. 7).

On first consideration, the above differences of $4.4^{\circ} \mathrm{C}$ may seem trivial, but it must be appreciated that rates of many physiological processes, including food digestion and assimilation, are thermolabile (Dawson 1975; Diefenbach 1975; Harlow, Hillman, and Hoffman 1976; Harwood 1979; Christian 1986). The aerobic metabolic rate of marine iguanas, for example, nearly trebles when $T_{b}$ rises by $10^{\circ} \mathrm{C}$ over the $T_{b}$ interval 24.8 to $41.6^{\circ} \mathrm{C}$ $\left(Q_{10}=2.9\right.$; Bennett, Dawson, and Bartholomew 1975). If the digestive and assimilative functions of marine iguanas share this thermal sensitivity, then the rates of energy storage and growth of this sessile iguana are $62 \%$ of those it could attain by maximizing $\mathrm{T}_{\mathrm{b}}$.

It thus appears that large adult iguanas exploit the thermal potential of their environment to a lesser extent than subadult lizards. This may reflect size-related differences in benefits compared to associated costs of thermoregulation in these ectotherms. We suggest that intertidal feeders have more to gain by maximizing $T_{b}$ than do subtidally-feeding lizards. This follows from both reproductive and allometric considerations. Because the polygynous mating system of marine iguanas favors large males and requires that females be of a particular size before breeding (Trillmich 1983), rapid growth of juvenile iguanas would have an important consequence for their fitness. In addition, predator pressure favors rapid growth

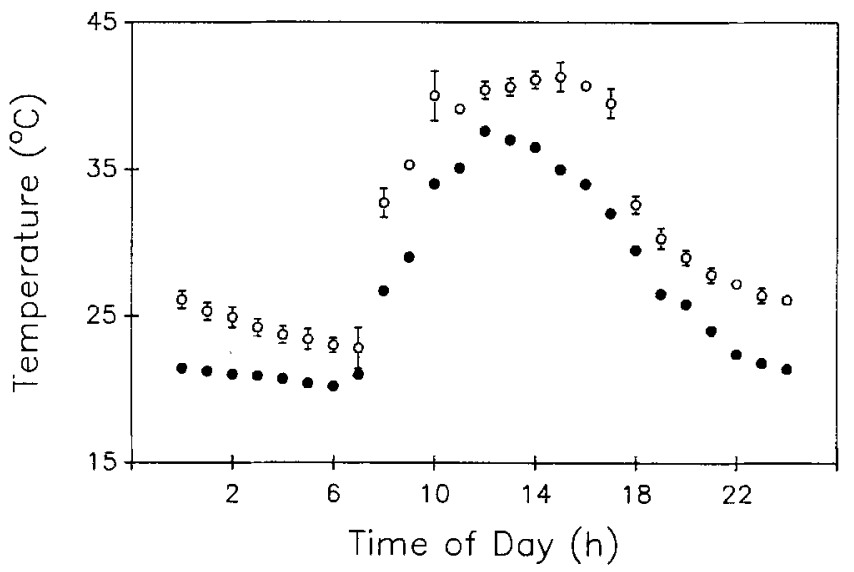

Fig. 7. Composite of highest hourly diurnal body temperatures recorded for large male marine iguanas (mean $\pm 95 \%$ confidence interval of 3 highest values) over the course of the study and predicted maximal nocturnal values (open circles) to values recorded for 24 consecutive h from a large male marine iguana ( filled circles). Maximal nighttime $T_{b}$ values used for this comparison are based on temperatures measured beneath clustered sub-adult lizards and assumes that the large iguanas would share these temperatures if they were to join the cluster as avian predators on these lizards feed mainly on smaller marine iguanas (Carpenter 1966; Boersma 1982). Their small size, however, limits their food procurement in two important ways: firstly, by their being restricted to intertidal foraging, their feeding is constrained spatially and temporally and, secondly, allometric considerations suggest that smaller individuals provision proportionately less of their energy needs with each gut filling than do larger forms (Calder 1984). The daily energy expenditure (DEE) of marine iguanas, for example, scales as a function of body mass 0.68 (Nagy and Shoemaker 1984). This means that a $3-\mathrm{kg}$ lizard would have a DEE little more than twice that of a $1 \mathrm{~kg}$ individual. By contrast, the gut content of another hebivorous iguanid, Iguana iguana, remains the same proportion of total body mass throughout development (Troyer 1984). If marine iguanas share this scaling, then smaller lizards will have less food available for maintenance and growth with each gut filling than larger ones. Juveniles could offset this limitation somewhat by topping up their gut contents at every foraging opportunity and reducing processing time between meals through effective behavioral thermoregulation. This pattern of feeding has been described for another herbivorous ectotherm, the tent caterpillar (Malacosoma americanum, Casey et al. 1988). Interestingly, the amount of food processed daily by these caterpillars, as well as their growth rate, is highly sensitive to $T_{b}$ which most caterpillars attempt to maintain at high daytime levels through behavioral thermoregulation (Casey et al. 1988; Knapp and Casey 1986). Observations that marine iguanas smaller than $1.4 \mathrm{~kg}$ normally feed daily, whereas those larger than about $2 \mathrm{~kg}$ often feed every $2-3$ days (Trillmich 1983; Trillmich and Trillmich 1986; Nagy and Shoemaker 1984; this study) support the notion that juveniles are maximizing food throughput. The nightly clustering of juveniles also appears adaptive in this context, judging by a study of another herbivorous tropical iguana, Cyclura nubila, whose feeding and growth rates increased directly with its nighttime body temperature (Christian 1986).

Another size and gender-ordered behavioral difference in these lizards concerns fighting. We only observed agonistic interactions between large males, usually when one male approached another male while it was basking. These aggressive tendencies between large males may partly be responsible for their minimal movement about the study site during the day and their habit of sleeping alone. A question remains, however, as to why these animals avoid the thermal benefits of feeding at dawn to instead feed early in the afternoon. Three possibilities occur to us: 1) iguanas may wait until their $T_{b}$ reaches a particular value before initiating foraging; 2) they avoid hyperthermia by entering the cooler water at a time of day when thermoregulation is difficult; and/or 3) they select feeding times that precede periods with the greatest potential for rewarming. We will consider each of these possibilities separately, although they are thermally interrelated.

If subtidal feeding were initiated only after attainment of particular $T_{b}$ 's, we would expect the modal times for this activity to vary as functions of climatic conditions. Over the course of our study, however, modal subtidal feeding times were relatively invariant and showed no pattern of being earlier on mornings favoring more rapid 
(low wind speeds; high insolation) or less rapid (high wind speeds; overcast) body warming. Furthermore, the telemetered $\mathrm{T}_{\mathrm{b}}$ 's of iguanas entering seawater ranged from 24.9 to $37.6^{\circ} \mathrm{C}$ during our study (Bartholomew and Vleck, pers. comm.). Because a number of large iguanas reach this range of $\mathrm{T}_{\mathrm{b}}$ 's by $0900 \mathrm{~h}$, but do not feed at this time, we dismiss the idea that large iguanas are restricted thermally to feeding at midday. We should point out, however, that all $\mathrm{T}_{\mathrm{b}}$ 's below $32^{\circ} \mathrm{C}$ involved individuals which resumed subtidal feeding after resting on offshore rocks.

The second suggestion, that large iguanas avoid overheating by feeding at midday, is not supported by either our behavioral observations or measurements of telemetered body temperature. If overheating were a problem, we would expect all large iguanas to enter the sea daily at this time of day. Instead, we only once saw all the large iguanas at our study site feeding the same day. This particular day did not differ significantly from others concerning its thermal characteristics, but it was associated with a very low tide at midday. Even on days with low wind speeds and high insolation, many large iguanas moved to the crest of the study site (Fig. 1), placed their forelimbs on nearby rocks, and directed their heads and anterior bodies towards the sun. From measurements of the surface areas of the two types of models, we found the effective radiational areas to range from $465 \mathrm{~cm}^{2}$ for the prostrate basking posture with the sun directly overhead to $170 \mathrm{~cm}^{2}$ for the upright model when sunpointing. Thus, a simple postural adjustment significantly reduces radiative heat gain while simultaneously facilitating both free and forced-convective heat losses from the elongate forebody. The efficacy of this configuration is indicated by the much lower operative temperatures of sunpointing models compared to prostrate basking ones (Fig. 6). Additionally, the lower operative temperatures of heads compared to other body regions (Fig. 6) coupled with their lower thermal masses (Pough and McFarland 1976) permits maintenance of brain temperature within vital limits through postural adjustment, even in the absence of shade.

We now consider the third suggestion, that the time used for subtidal feeding coincides with periods permitting the highest rates of rewarming. Evaluation of this possibility requires knowledge of how radiative and convective conditions varied spatially and temporally at our study site, as well as how these variations affected thermal exchanges with marine iguanas. The complex thermal interactions affecting a lizard's rate of warming are simplified to:

$\mathrm{dT}_{\mathrm{b}} / \mathrm{dt}=\mathrm{K}_{\mathrm{e}}\left(\mathrm{T}_{\mathrm{b}}-\mathrm{T}_{\mathrm{e}}\right) / \mathrm{C}$

where, $\mathrm{dT}_{\mathrm{b}} / \mathrm{dt}$ represents the rate of body temperature change, $\left(T_{b}-T_{e}\right)$ is the difference between the animal's core body temperature $\left(T_{b}\right)$ and the operative environmental temperature $\left(T_{e}\right), C$ is its thermal capacity, and $K_{e}$ is its overall thermal conductance (Bakken 1976b). Thermal measurements of marine iguana models not only permit evaluation of $T_{e}$ (Bakken 1976a), but also can be used to evaluate $K_{e}$ using cooling-curve analyses of models that are previously heated (Bakken 1976b). After evaluating $T_{e}$ 's and $K_{e}$ 's associated with sites which typified those receiving peak solar radiation in the morning (areas 5 and 6) and those which typified sites getting peak insolation early in the afternoon (areas 3 and 4), we conclude that the time and location used for landing by subtidal feeders afford them the highest probability for attaining maximal rates of rewarming on a given day. Thus, although several areas have similar peak rates of solar irradiation (Fig. 3), only areas 3 and 4 have consistently high insolation levels coupled with low wind speeds occurring just after midday.

The daily use of wind-protected sites for basking has also been observed in Galápagos land iguanas (Christian and Tracy 1983). At some locations in the Galápagos, there is a protracted weather condition called the Garua which is associated with cool, foggy days. During the Garua season, land iguanas regularly selected microhabitats that were leeward to the prevailing southeasterly winds but exposed to afternoon sun. By actively moving about their home ranges, these land iguanas were able to maximize the time they spent at preferred $T_{b}$ each day (Christian and Tracy 1983). This is similar to the pattern of microhabitat use we observed for juvenile marine iguanas at our study site, but distinctively different to that of the larger adults. Striking thermoregulatory differences between juvenile and adult ectotherms have been reported for the Western toad (Bufo boreas; Lillywhite et al. 1973) and we expect that, with close scrutiny, size-ordered changes in behavioral exploitation of thermal environments will be noted for many other ectothermic animals.

A question remains concerning the advantage for subtidally-foraging marine iguanas to warm as rapidly as possible following their emergence from the water. We suggest that submarine feeding by these lizards perturbs their metabolic and ionic homeostasis and that the time required for recovery from these disturbances is temperature dependent. Like their terrestrial relatives, marine iguanas rely mainly on anaerobiosis when pushed to exertion, particularly when body temperatures are below preferred levels (Bennett et al. 1975; Bartholomew et al. 1976). Despite this, blood lactate levels in post-prandial individuals do not differ significantly from pre-foraging levels, suggesting they do not rely on anaerobiosis while foraging (Gleeson 1980a). We note, however, that one of the ten iguanas sampled in the latter study had blood lactate levels reflecting extensive anaerobiosis. Regardless of how foraging effort is supported metabolically, the rate of recovery from both aerobic and anaerobic exercise is strongly temperature dependent, being about two-fold faster at $\mathrm{T}_{\mathrm{b}}$ 's of $35^{\circ} \mathrm{C}$ than at $\mathrm{T}_{\mathrm{b}}$ 's of $25^{\circ} \mathrm{C}$ (Gleeson $1980 \mathrm{~b}$ ). Because the extent of an iguana's recovery from previous exertion directly affects its subsequent endurance (Gleeson 1980b), lizards warming quickly following a foraging bout will be able to resume terrestrial activities sooner and sustain them for longer periods than lizards having lower $T_{b}$ 's. Such capability may be especially important to large adult males which may actively maintain territories outside the breeding season (Trillmich 1983).

Another physiological perturbation likely to result from submarine feeding concerns ion balance. As for other herbivores, the plant diet of marine iguanas is potassiumrich but, unlike terrestrial plants, marine algae also 
contain substantial amounts of sodium and chloride (Shoemaker and Nagy 1984). Subtidal foragers, however, are likely to ingest proportionately more $\mathrm{NaCl}$ per foraging bout than intertidal foragers for two reasons. Firstly, unless exposed intertidal algae are in a splash zone, the amount of seawater ingested with them will be less than for submerged algae. Secondly, the amount of food ingested by intertidal foragers, which feed daily, should be proportionately less than by subtidal feeders, particularly the largest ones which feed every two to three days. From estimates of daily $\mathrm{NaCl}$ intake by free-living iguanas (Shoemaker and Nagy 1984), a 2-kg marine iguana feeding every 3 days would ingest 87.0 and $94.2 \mathrm{mM}$ of $\mathrm{Na}^{+}$and $\mathrm{Cl}^{-}$, respectively, at each feeding. If the extracellular fluid (ECF) volumes of marine iguanas are similar to those measured in other iguanas (Minnich 1968; Nagy 1972), the amount of $\mathrm{NaCl}$ ingested by this $2-\mathrm{kg}$ iguana is more than $2 / 3$ the total amount normally found in its entire ECF. This would result in a marked increase in ECF volume, and, accordingly, produce a rise in plasma volume. Such fluid shifts might well compromise cardiovascular function until the dietary $\mathrm{NaCl}$ was excreted.

This high potential for ECF volume expansion following a meal gives added significance to the unusually high capacity for extrarenal salt excretion by marine iguana nasal salt glands (Dunson 1969, 1976). Dunson (1969) noted that the rates of nasal salt secretion were highest within the first few $h$ of salt loading and declined steadily as the $\mathrm{NaCl}$ was eliminated. We did note that many iguanas repeatedly sprayed fluid from their nostrils while basking after a feeding bout. We expect that the active transport processes underlying nasal salt secretion in marine iguanas are thermolabile, and we concur with Dunson (1969) that the thermosensitivity of this process needs to be evaluated.

We recognize the risk of attempting to impart adaptive significance to the timing of subtidal feeding by marine iguanas from the limited data we have gathered. If our interpretations are correct, we would expect the timing of subtidal feeding to vary from one colony to another and even seasonally at the same site when, for example, the southerly winds were no longer a dominant feature of morning weather conditions. Unfortunately, we have not returned to our study site to test this hypothesis but are intrigued by observations of colonies at different sites where modal times for subtidal feeding fell mainly between 1000 and $1100 \mathrm{~h}$ (Trillmich and Trillmich 1986).

We are left with the impression that the size-ordered differences we observed in marine iguana thermoregulatory behavior reflect underlying ontogenetic changes in costs and benefits of thermoregulation due to differences in predator pressure, quantity of food and electrolytes taken at each feeding, mode of foraging, and agonistic tendencies. Further insight into the dynamics of these interactions would result from thermoregulatory studies of subtidal feeders under variable conditions of energy need and availability. Examples include post-breeding periods when males have depleted their energy reserves (Trillmich 1983) and during El Niño conditions which are associated with greatly reduced food availability (F. Trillmich, pers. comm.).
Acknowledgments. We acknowledge the Government of Ecuador for their support, the cooperation and understanding of Miguel Cifuentes (Director of the Galápagos National Park), the assistance of Hendryk Hoeck (Director of the Charles Darwin Biological Station), the leadership and support of George A. Bartholomew (chief scientist of the expedition), and the help and encouragement of all those aboard the R/V Alpha Helix. George S. Bakken greatly facilitated our meteorological measurements and their subsequent analysis and photographed the iguana models for the subsequent surface area determinations which were evaluated by Lee Astheimer. William W. Willmarth provided a low-speed wind tunnel for anemometer calibration. Keith Christian, Joe Travis, and two anonymous reviewers provided valuable comments to an earlier draft of this manuscript. This research was supported by U.S. National Science Foundation grant DEB 77-00183.

\section{References}

Bakken GS (1976a) A heat transfer analysis of animals: unifying concepts and the application of metabolism chamber data to field ecology. J Theor Biol 60: 337-384

Bakken GS (1976b) An improved method for determining thermal conductance and equilibrium body temperature with cooling curve experiments. J Therm Biol 1: 169-175

Bakken GS, Gates DM (1975) Heat-transfer analysis of animals: Some implications for field ecology, physiology, and evolution. In: Gates DM, Schmerl RB (eds) Perspectives of biophysical ecology. Springer Verlag, New York, pp 255-290

Bakken GS, Vanderbilt VC, Buttemer WA, Dawson WR (1978) Avian eggs: Thermoregulatory value of very high near-infrared reflectance. Science 200: 321-323

Bartholomew GA (1966) A field study of temperature relations in the Galápagos marine iguana. Copeia 1966: 241-250

Bartholomew GA, Bennett AF, Dawson WR (1976) Swimming, diving, and lactate production of the marine iguana, Amblyrhynchus cristatus. Copeia 1976: 709-720

Bennett AF, Dawson WR, Bartholomew GA (1975) Effects of activity and temperature on aerobic and anaerobic metabolism in the Galápagos marine iguana. J Comp Physiol 100: 317-329

Boersma PD (1982) The benefits of sleeping aggregations in marine iguanas, Amblyrhynchus cristatus. In: Burghardt GM, Rand RS (eds) Iguanas of the World. Noyes Publ., New Jersey, USA pp 292-300

Boersma PD (1984) An ecological study of the Galápagos marine iguana. In: Bowman RI, Berson M, Leviton AE (eds) Pattern of evolution in Galápagos organisms. Am Assoc Adv Sci Pac Div, San Francisco, USA, pp 157-176

Buttemer WA (1981) The thermal significance of winter roost-site selection by American goldfinches (Carduelis tristis). $\mathrm{PhD}$ dissertation, University of Michigan, Ann Arbor

Calder WA III (1984) Size, function, and life history. Harvard University Press. Cambridge, Massachusetts, USA

Carpenter CC (1986) The marine iguana of the Galápagos Islands, its behavior and ecology. Proc Calif Acad Sci 34: 329-376

Casey TM, Joos B, Fitzgerald TD, Yurlina ME, Young PA (1988) Synchronized group foraging, thermoregulation, and growth of Eastern tent caterpillars in relation to microclimate. Physiol Zool $61:$ 373-377

Christian KA (1986) Physiological consequences of nighttime temperature for a tropical, herbivorous lizard (Cyclura nubila). Can J Zool 64: 836-840

Christian KA, Tracy CR, Porter WP (1983) Seasonal shifts in body temperature and use of microhabitats by Galápagos land iguanas (Conolophus pallidus). Ecology 64: 463-468

Christian KA, Tracy CR, Porter WP (1984) Physiological and ecological consequences of sleeping-site selection by the Galápagos land iguana (Conolophus pallidus). Ecology 65; 752-758

Dawson WR (1975) On the physiological significance of the preferred body temperatures of reptiles. In: Gates DM; Schmerl RB (eds) Perspectives in biophysical ecology. Springer, Berlin, pp 443-473 
Diefenbach CO daC (1975) Gastric function in Caiman crocodilus (Crocodylia: Reptilia)-I. Rate of gastric digestion and gastric motility as a function of temperature. Comp Biochem Physiol 51A: $259-265$

Dunson WA (1969) Electrolyte excretion by the salt gland of the Galápagos marine iguana. Am J Physiol 216: 995-1002

Dunson WA (1976) Salt glands in reptiles. In: Gans C, Dawson WR (eds) Biology of the Reptilia, Vol. 5. Physiology A. Academic Press, New York, pp 413-445

Gates DM (1980) Biophysical ecology. Springer New York, USA

Gleeson TT (1980a) Lactic acid production during field activity in the Galápagos marine iguana, Amblyrhynchus cristatus. Physiol Zool 53: 157-163

Gleeson TT (1980b) Metabolic recovery from exhaustive activity by a large lizard. J Appl Physiol Resp Environ Exercise Physiol 48: 689-694

Harlow HJ, Hillman SS, Hoffman M (1976) The effect of temperature on digestive efficiency in the herbivorous lizard Dipsosaurus dorsalis. J Comp Physiol 111: 1-6

Harwood RH (1979) The effect of temperature on the digestive efficiency of three species of lizards, Cnemidophorus tigris, Gerrhonotus multicarinatus, and Sceloporus occidentalis. Comp Biochem Physiol 63A: 417-433

Huey RB, Slatkin M (1976) Costs and benefits of lizard thermoregulation. Q Rev Biol 51: 363-384

Knapp R, Casey TM (1986) Activity patterns, behavior and growth in gypsy moth and Eastern tent caterpillars. Ecology 67: 598-608

Lillywhite HB, Licht P, Chelgren P (1973) The role of behavioral thermoregulation in the growth and energetics of the toad Bufo boreas. Ecology 54: 375-383
Minnich JE (1968) Maintenance of water and electrolyte budget by the desert iguana, Dipsosaurus dorsalis. PhD dissertation. University of Michigan, Ann Arbor

Nagy KA (1972) Water and electrolyte budgets of a free-living desert lizard, Sauromalus obesus. J Comp Physiol 79: 39-62

Nagy KA, Shoemaker VH (1984) Field energetics and food consumption in the Galápagos marine iguana, Amblyrhynchus cristatus. Physiol. Zool. 57: 281-290

Norris DJ (1974) Calibration of pyranometers in inclined and inverted positions. Solar Energy 16: 53-55

Pough FH (1973) Lizard energetics and diet. Ecology 54: 837-844

Pough FH, McFarland WN (1976) A physical basis for head-body temperature differences in reptiles. Comp Biochem Physiol 53A: 301-303

Shoemaker VH, Nagy KA (1984) Osmoregulation in the Galápagos marine iguana, Amblyrhynchus cristatus. Physiol Zool 57:291-300

Trillmich KGK (1983) The mating system of the marine iguana (Amblyrhynchus cristatus). Z. Tierpsych 63: 141-172

Trillmich KGK, Trillmich F (1986) Foraging strategies of the marine iguana, Amblyrhynchus cristatus. Behav Ecol Sociobiol 18: 259-266

Troyer K (1984) Structure and function of the digestive tract of a herbivorous lizard Iguana iguana. Physiol Zool 57: 1-8

Vleck D, Gleeson TT, Bartholomew GA (1981) Oxygen consumption during swimming in Galápagos marine iguanas and its ecological correlates. J Comp Physiol 141: 531-536

Werner EE, Hall DJ (1988) Ontogenetic habitat shifts in bluegill: the foraging rate-predation risk trade-off. Ecology 69: 1352-1366

White FN (1973) Temperature and the Galápagos marine iguana: Insights into reptilian thermoregulation. Comp Biochem Physiol 45: $503-513$ 